\title{
Pathoanatomy and clinical outcomes following operative treatment of supination adduction type II medial malleolus fractures - a cohort study
}

\author{
Jin Zhang ${ }^{1,2}$, Yan Zhang ${ }^{2}$, Jingqi Liang ${ }^{2}$, Peilong Liu ${ }^{2}$, Hongmou Zhao ${ }^{2}$ \\ ${ }^{1}$ Department of Orthopedic Surgery, Guizhou Provincial People's Hospital, Guiyang, China; ${ }^{2}$ Department of Foot and Ankle Surgery, Honghui \\ Hospital Affiliated to Medical College of Xi'an Jiaotong University, Xi'an, China \\ Contributions: (I) Conception and design: J Zhang; (II) Administrative support: H Zhao; (III) Provision of study materials or patients: Y Zhang, J \\ Liang; (IV) Collection and assembly of data: J Liang, P Liu; (V) Data analysis and interpretation: J Zhang, H Zhao; (VI) Manuscript writing: All \\ authors; (VII) Final approval of manuscript: All authors. \\ Correspondence to: Hongmou Zhao. Department of Foot and Ankle Surgery, Honghui Hospital Affiliated to Medical College of Xi'an Jiaotong \\ University, Xi'an 710054, China. Email: zhao_hongmou@hotmail.com.
}

Background: The purpose of the current study was to retrospectively clarify the anatomic character and evaluate the mid-term operative outcomes for vertical medial malleolar fractures (MMFs).

Methods: A total of 53 patients with supination adduction (SAD) type II MMFs treated with open reduction and internal fixation (ORIF) between March 2009 and June 2013 were included. We reviewed the patients' preoperative X-ray and computed tomography (CT) to determine the pathoanatomic characteristics of medial malleolus fractures. Buttress plate lag screws fixation had been applied. Complications and treatment failures were recorded; the American Orthopedic Foot and Ankle Society (AOFAS) ankle-hindfoot score and the visual analogue scale (VAS) were used to evaluate the functional outcomes.

Results: For the 53 patients, only 39.6\% cases with simple vertical MMFs. The mean distal tibial articular surface (DTAS) involvement in the MMF was $16.5 \% \pm 11.6 \%$ (range, $0-47 \%$ ). The mean follow up time was $62.4 \pm 14.1$ [44-91] months. There were 7 cases of traumatic osteoarthritis (TOA), and 3 cases of failure were reported in the screw fixation group. The mean AOFAS score was 80.6 15.8 points, and the mean VAS score was $2.1 \pm 1.7$ points, with a good to excellent rate (GTE) of $81.1 \%$. No significant difference was found in comparing the AOFAS, VAS, GTE, incision relative complication rate, infection rate, loss of reduction (LoR) rate, and TOA rate between groups $(\mathrm{P}>0.05)$. The participants in the buttress plate group reached a shorter mean full weight-bearing (FWB) time $(\mathrm{P}=0.04)$.

Conclusions: More than $60 \%$ vertical MMFs are with one or more characteristics of medial cortex comminuted fractures, or die-punch fragments, or medial joint compression. And patients with die-punch fragment, medial joint compression, LoR, large DTAS involvement and small fracture line angle (FLA) were positively correlated with the fair to poor results. Lag screw fixation should be cautiously used in vertical MMF patients with comminuted medial cortex.

Keywords: Ankle fracture; medial malleolar fracture (MMF); anatomic character; internal fixation; functional outcome

Submitted May 08, 2021. Accepted for publication Jul 13, 2021.

doi: 10.21037/apm-21-1505

View this article at: https://dx.doi.org/10.21037/apm-21-1505 


\section{Introduction}

Ankle fracture is a common injury addressed by orthopedic surgeons, with an estimated 260,000 Americans sustaining an ankle fracture annually (1). However, supination adduction (SAD) ankle fracture does not present as commonly, and has been reported to comprise $4-5 \%$ of all ankle fractures $(2,3)$. Additionally, vertical type medial malleolar fracture (MMF) has been shown to account for about $6 \%$ of all MMFs (4). Although surgical treatment with open reduction and internal fixation (ORIF) is generally the accepted form of treatment for intraarticular fractures, clinical research focused on SAD is scarce.

The main cause of SAD type II MMFs is vertical Violence, the injury mechanism is similar to that of pilon fractures, especially posterior pilon fracture (5-7). This type of MMF presents with relatively vertical fracture lines, and may sometimes be characterized by a proximal medial cortical comminuted fracture (Figure 1A), a die-punch fragment (Figure 1B), compression and collapse of the medial part of distal tibial articular surface (DTAS) (Figure 1C), and sometimes these characteristics may coexist. High surgical technical expertise is required for the treatment of this type of
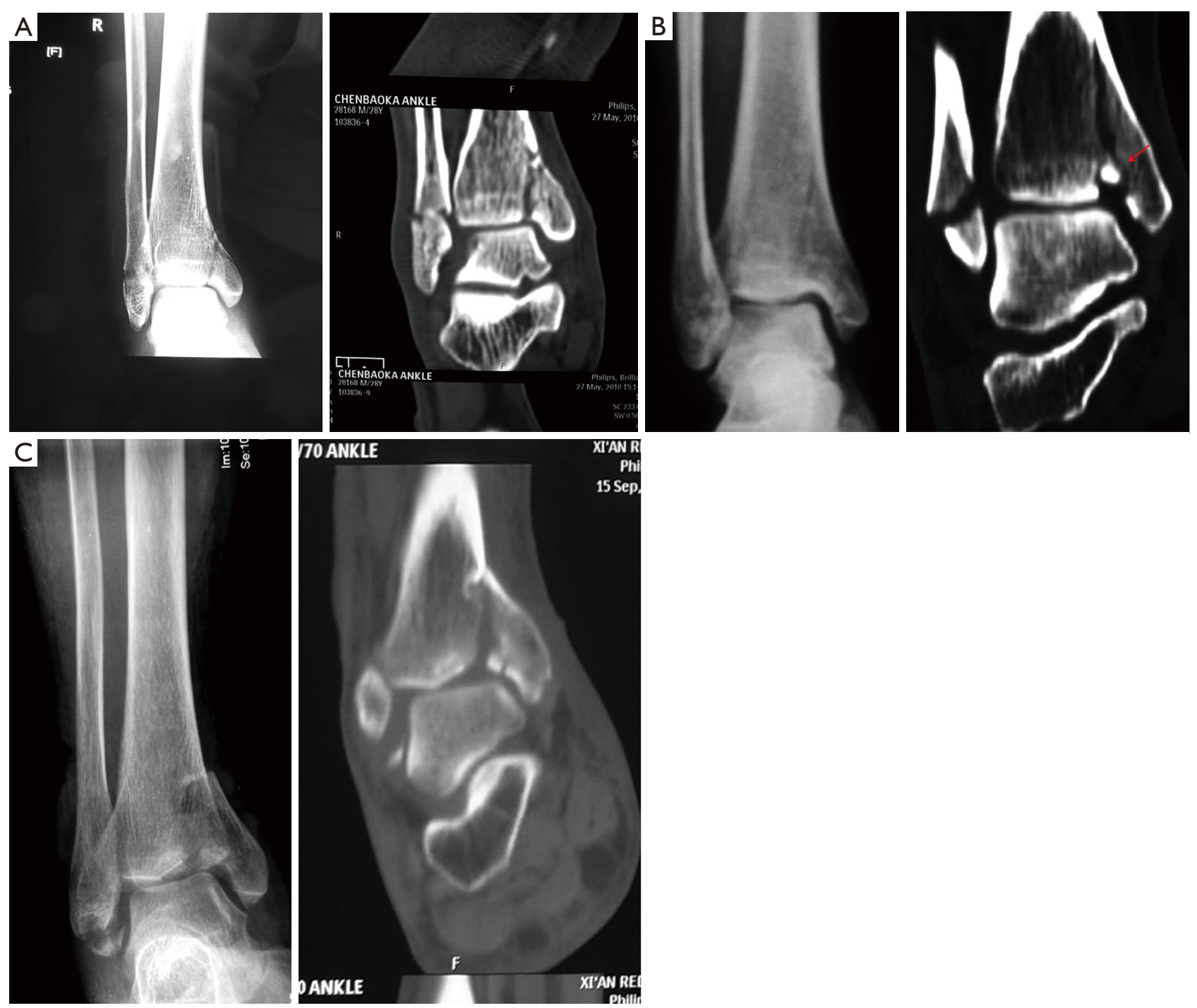

Figure 1 Some MMF types of SAD-II, (A) proximal medial cortical comminuted fracture, (B) die-punch fragment (the red arrow: the diepunch fragment), (C) compression and collapse of the medial part of DTAS. MMF, medial malleolar fracture; SAD, supination adduction; DTAS, distal tibial articular surface. 

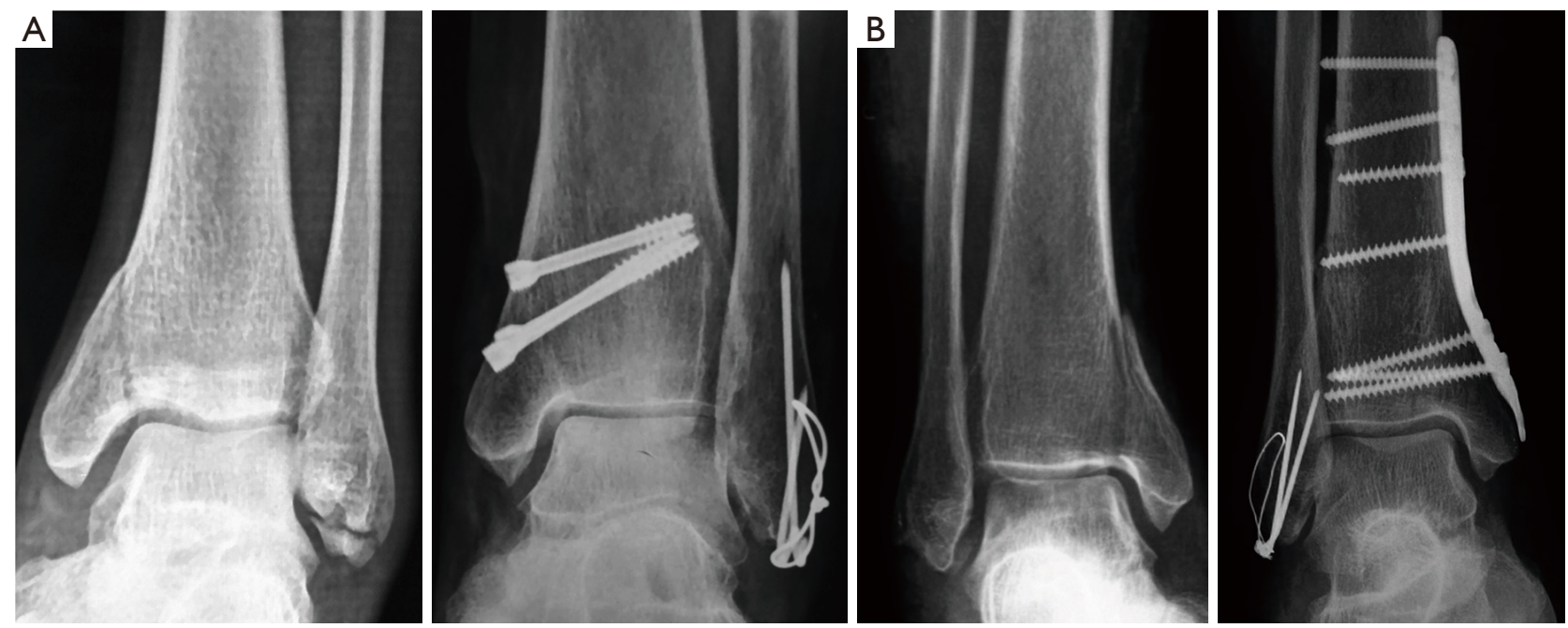

Figure 2 Different fixation for vertical MMF. (A) Screws fixation of SAD type II MMF; (B) buttress plate fixation of SAD type II MMF. MMF, medial malleolar fracture; SAD, supination adduction.

MMFs, and the internal fixation methods are controversial. A biomechanical study reported that both simple screws fixation and buttress plate fixation could attain a similar mechanical strength for this type of fracture (8), but some others have reported that the buttress plate provided better support to vertical MMFs in comparison with unicortical or bicortical screws fixation (9). To date, no clinical comparative study has been reported that has solely focused on the internal fixation methods for SAD type II MMFs. The purpose of the current study was to retrospectively clarify the anatomic characters and compare the functional outcomes and complications of pathoanatomic features and different internal fixations in the treatment of SAD type II MMFs.

We present the following article in accordance with the STROBE reporting checklist (available at https://dx.doi. org/10.21037/apm-21-1505).

\section{Methods}

All procedures performed in this study involving human participants were in accordance with the Declaration of Helsinki (as revised in 2013). The study was approved by institutional ethics board of the Honghui Hospital Affiliated to Medical College of Xi' an Jiaotong University (No.: 20170003). Individual consent for this retrospective analysis was waived. The authors retrospectively analyzed the characteristics of SAD type II MMFs thorough X-ray and computed tomography (CT), and the outcomes of buttress plate fixation or screws fixation between March
2009 and June 2013. The inclusion criteria were as follows: (I) adults over 18 years old; (II) acute SAD type II ankle fracture; (III) MMF was treated with open reduction and buttress plate fixation or screws fixation; (IV) at least 2 years follow up. The exclusion criteria were as follows: (I) surgical fixation beyond 14 days from the time of injury; (II) grade II or III open ankle fractures according to GustiloAnderson classification (10); (III) combined with talus body fracture requiring fixation; (IV) pathological fractures; (V) preoperative dysfunction of the injured limb; (VI) no preoperative or follow-up X-ray and CT.

\section{Treatment methods}

For the MMFs, an anteromedial incision was made. The incision enabled a view of the anteromedial aspect of the joint, permitting accurate alignment of the fracture. For patients with a die-punch fragment, or compression and collapse of the medial part of DTAS, an anatomical reduction under direct vision from this incision was able to be achieved. Cancellous allograft was used in the case of bone defect after the DTAS reduction. Finally, the MMF was fixed either with screws (Figure $2 A$ ) or a buttress plate (Figure 2B). Then, fluoroscopy was used to ensure the reduction and positioning of the hardware.

\section{Postoperative management}

The postoperative rehabilitation protocol for all participants 

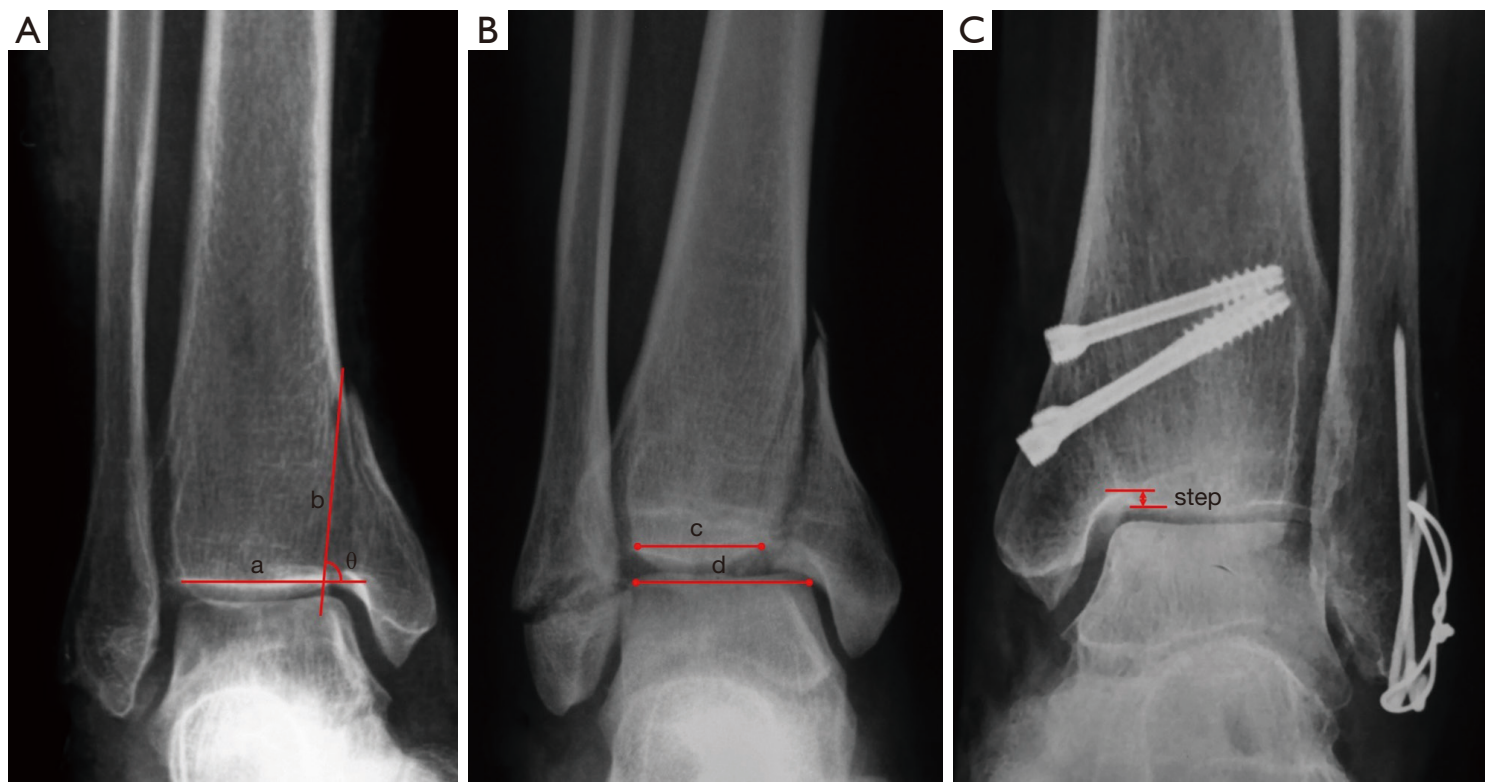

Figure 3 Some variants in the text. (A) The FLA was measured between the DTAS line (a) and the major fracture line of the medial malleolus (b); (B) the DTAS\% involvement was calculated with the $(\mathrm{d}-\mathrm{c}) / \mathrm{d} \times 100 \%$; $(\mathrm{C})$ the LoR means the intraarticular step more than $1 \mathrm{~mm}$ at the follow-up time. FLA, fracture line angle; DTAS, distal tibial articular surface; LoR, loss of reduction

included active and passive motion exercises of the ankle and mid- and forefoot joints, isotonic and isometric exercises of the leg, and a night splint, commencing on the second postoperative day. Full weight-bearing (FWB) was initiated after the fracture site had reached bony union radiographically.

\section{Radiographic and clinical evaluation}

The pre-operative $\mathrm{X}$-rays and CT scans were retrospectively analyzed. The characteristics of MMFs were evaluated on coronal CT scans. The medial malleolus fracture line angle (FLA) was defined as the angle between major fracture line and DTAS line (Figure $3 A$ ) on the anterior-posterior ankle $\mathrm{X}$-ray. The method of DTAS\% involvement on anteriorposterior ankle $\mathrm{X}$-ray was calculated with the method on Figure 3B. Radiographs taken at the final follow-up time were compared with immediate postoperative radiographs for evidence of screw loosening, loss of reduction (LoR), and nonunion. LoR was defined as any shift in fracture position greater than $1 \mathrm{~mm}$ (Figure 3C). The final radiographs were also used to evaluate osteoarthritis; according to the van Dijk ankle osteoarthritis classification (11), stage-II and stage-III were defined as traumatic osteoarthritis (TOA) change.

The American Orthopedic Foot and Ankle Society (AOFAS) ankle-hindfoot score (12), and the visual analogue scale (VAS) were used for functional evaluation at the final follow-up time. The AOFAS scoring scale has a maximum of 100 points $(>91$ indicates an excellent result, $75-90=$ good result, $50-75=$ fair result, and $\angle 50=$ poor result). LoR was defined as any shift in fracture position greater than $2 \mathrm{~mm}$. Treatment failure was defined as fracture nonunion, malunion, or fixation failure requiring reoperation. Wound complication included dehiscence, skin edge necrosis, and delayed healing.

\section{Statistical analyses}

Descriptive statistics were calculated as mean \pm standard deviation (SD). Student's $t$-test was used to compare differences between groups for continuous variables; Pearson's chi-square test and Fisher's exact test were used for comparison of dichotomous variables. The level of significance was set at $\mathrm{P}=0.05$. Statistical analyses were performed with the software SPSS 17.0 (SPSS Inc., Chicago, IL, USA).

\section{Results}

\section{The basic informations}

Total of 53 participants, with 28 males and 25 females, were included in this study. The average age was $38.5 \pm 16.1$ [18-78] years. The mean follow up time was $62.4 \pm 14.1$ 
Table 1 Participant demographics

\begin{tabular}{|c|c|c|c|}
\hline Participant demographics & Buttress plate fixation $(n=30)$ & Screws fixation $(n=23)$ & $P$ value \\
\hline Left: right ratio & $8: 22$ & $12: 11$ & 0.06 \\
\hline Mean age (SD) & $36.8(14.8)$ & $40.7(17.7)$ & 0.39 \\
\hline BMI (SD) & $25.7(3.9)$ & $24.9(4.2)$ & 0.48 \\
\hline Lateral injury type & & & 0.62 \\
\hline Transverse fracture & 19 & 13 & \\
\hline Avulsion fracture & 9 & 8 & \\
\hline Ligament rupture & 2 & 2 & \\
\hline
\end{tabular}

SD, standard deviation; BMI, body mass index.

[44-91] months. Causes of fracture included 24 falls from a height, 17 sprains, and 12 motor cycle accidents. Combined injuries included 6 fifth metatarsal base fractures, 2 Lisfranc injuries, 3 distal radius fractures, and 1 femoral shaft fracture. A total of $30 \mathrm{MMFs}$ were fixed with a buttress plate, and 23 were fixed with screws. No significant difference of basic information was detected between the two groups (Table 1).

\section{MMF characters}

For the included patients, $21(39.6 \%)$ cases with simple vertical MMFs; 25 (47.2\%) cases with medial cortex comminuted fractures; $19(35.8 \%)$ cases with diepunch fragments; and $18(34.0 \%)$ cases with medial joint compression. Actually, 19 (35.8\%) cases coexisted two or three of the characteristics; 2 (3.8\%) cases coexisted with medial cortex comminuted fractures and die-punch fragments; 2 (3.8\%) cases coexisted with medial cortex comminuted fractures and joint compression; 3 (5.7\%) cases coexisted with die-punch fragments and joint compression; and $12(22.6 \%)$ cases coexisted with the three characteristics (Figure 4).

\section{The effects on prognosis of different MMF}

The AOFAS score in patients with medial cortex comminuted fractures was significantly lower than whose patients without these characteristics $(\mathrm{P}=0.01)$; as well as those patients with die-punch fragments and medial joint compression
$(\mathrm{P}<0.01)$. The LoR rate was significantly higher in patients with die-punch fragments $(\mathrm{P}=0.03)$; and the TOA rate was significantly higher in patients with medial joint compression $(\mathrm{P}=0.04)$ (Table 2).

\section{The data about the DTAS\% and FLA}

The mean DTAS\% was $16.5 \% \pm 11.6 \%$ (range, $0-47 \%$ ). Nine $(17.0 \%)$ cases without involved of DTAS; 17 (32.1\%) cases involved less than $10 \% ; 16(30.2 \%)$ cases involved between $10 \%$ and $20 \%$; and $11(20.8 \%)$ cases involved more than $20 \%$. The mean medial malleolus FLA was $80.8^{\circ} \pm 6.1^{\circ}$ (range, $\left.58^{\circ}-90^{\circ}\right)$. Thirty $(56.6 \%)$ cases were with FLA more than $80^{\circ}$; and $19(35.8 \%)$ cases between $70^{\circ}$ and $80^{\circ}$; and 4 $(7.5 \%)$ cases less than $70^{\circ}$.

\section{The relationship between prognosis and the DTAS\% and FLA}

LoR was detected in 7 cases during follow up, along with 7 cases of TOA. The TOA incidence increased and positively correlated with the increase of DTAS\% involvement, as well as the LoR incidence (Figure 5A); and the mean AOFAS decreased with the increase of DTAS\% involvement. However, no significant difference was detected with the numbers available (Table 3). The TOA and LoR incidence increased and with the decrease of medial malleolus FLA (Figure 5B), and the LoR incidence was significantly increased in cases with FLA less than $70^{\circ}$ 
A

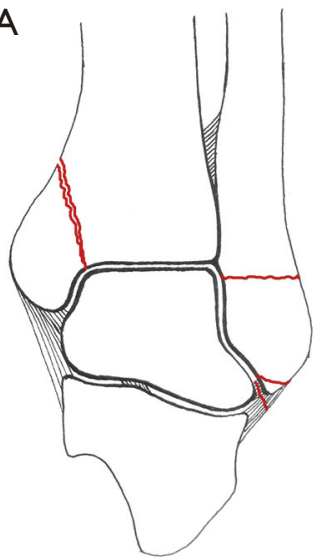

Simple fracture

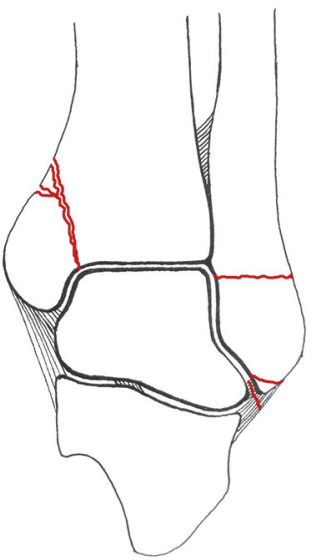

Medial cortex comminuted fractures (A)

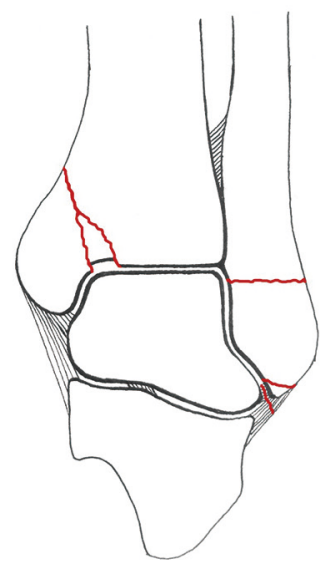

With die-punch fragments $(B)$

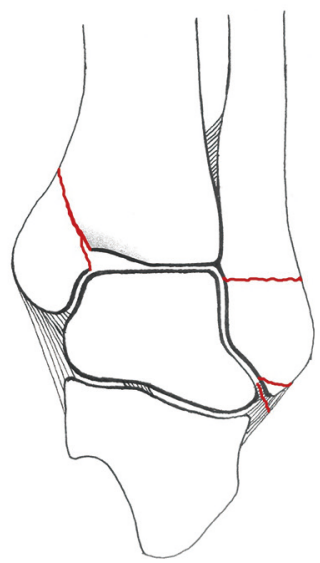

Joint compression fractures (C)

\section{B}

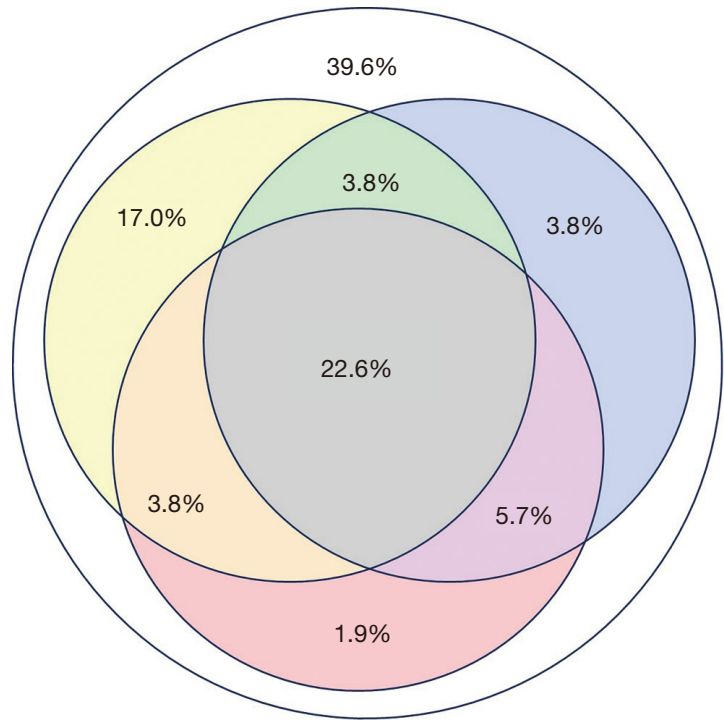

$\bigcirc$ Simple fracture

Medial cortex comminuted fractures $(A)$

With die-punch fragments $(B)$

$\bigcirc$ Joint compression fractures (C)

Combined $A$ and $B$

$\bigcirc$ Combined $B$ and $C$

Combined $\mathrm{A}$ and $\mathrm{C}$

Combined A, B and C

Figure 4 The percentage of the medial malleolus fractures with different pathoanatomic characteristics.

Table 2 The outcomes of different characteristics of MMFs ( $\mathrm{n}=53)$

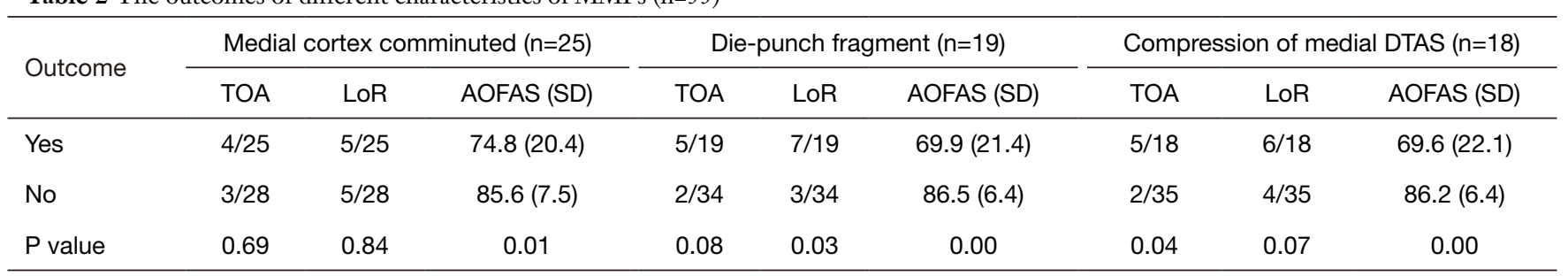

MMF, medial malleolar fracture; DTAS, distal tibial articular surface; TOA, traumatic osteoarthritis; LoR, loss of reduction; AOFAS, American Orthopedic Foot and Ankle Society; SD, standard deviation.

while compared with overall mean $(\mathrm{P}=0.03)$. The mean AOFAS decreased with the decrease of medial malleolus FLA, but no significant difference was detected with the numbers available (Table 3).
The comparison between the buttress plate and screws fixation

The mean AOFAS ankle and hindfoot score at final 

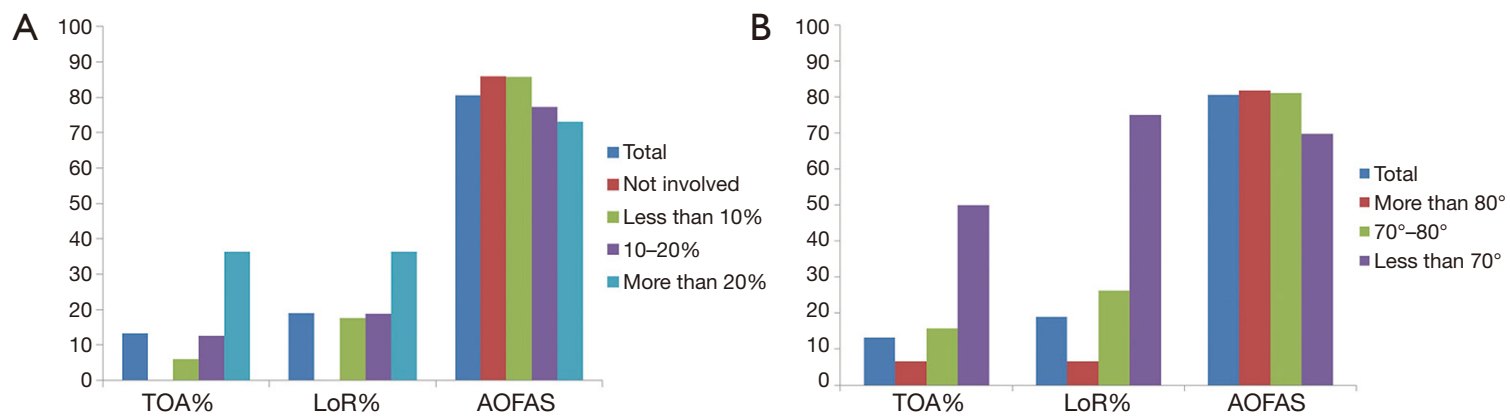

Figure 5 The effect to outcome of different DTAS\% and FLA. (A) Clinical outcomes of different DTAS involvement in medial malleolus fractures; (B) clinical outcomes of different medial malleolus FLA patients. DTAS, distal tibial articular surface; FLA, fracture line angle.

Table 3 The outcomes of medial malleolus fractures with different DTAS involvements and FLAs

\begin{tabular}{|c|c|c|c|}
\hline Operative outcome & TOA (\%) $\left[\mathrm{P}^{*}\right]$ & $\operatorname{LoR}(\%)\left[\mathrm{P}^{\star}\right]$ & AOFAS (SD) [P*] \\
\hline \multicolumn{4}{|l|}{ DTAS involvement } \\
\hline Not involved $(\mathrm{n}=9)$ & $0(0.0)[0.58]$ & $0(0)[0.33]$ & $85.9(6.4)$ [0.33] \\
\hline Less than $10 \%(n=17)$ & $1(5.9)[0.67]$ & 3 (17.6) [1.00] & $85.8(9.2)[0.20]$ \\
\hline More than $20 \%(n=11)$ & $4(36.4)[0.09]$ & $4(36.4)[0.24]$ & $73.1(16.3)[0.16]$ \\
\hline \multicolumn{4}{|l|}{ FLA with DTAS } \\
\hline More than $80^{\circ}(n=30)$ & $2(6.6)[0.48]$ & $2(6.7)[0.20]$ & 81.7 (17.0) [0.77] \\
\hline $70^{\circ}-80^{\circ}(n=19)$ & $3(15.8)[0.72]$ & $5(26.3)[0.52]$ & $81.1(14.7)$ [0.90] \\
\hline
\end{tabular}

*, the $P$ value was calculated comparing with the total results. DTAS, distal tibial articular surface; FLA, fracture line angle; TOA, traumatic osteoarthritis; LoR, loss of reduction; AOFAS, American Orthopedic Foot and Ankle Society; SD, standard deviation.

follow up or before revision surgery was $80.6 \pm 15.8$ [12-97] points. The mean VAS score during walking was $2.1 \pm 1.7[0-8]$ points. The good to excellent rate (GTE) was $81.1 \%(43 / 53)$. With the numbers available, no significant difference was detected when comparing the functional outcomes between the buttress plate fixation and screws fixation groups (Table 4). However, the mean FWB time was significantly shorter in the buttress plate fixation group $(\mathrm{P}=0.04)$.

\section{The complication data}

There were 5 wound complications, 3 superficial infections, and all were treated conservatively without further surgical intervention. Surgical failure was diagnosed in 3 cases, all of which were fixed with screws for the MMFs. No significant difference was detected when comparing the complication rates between groups (Table 4).

\section{Discussion}

The Lauge-Hansen classification system was intended to predict mechanism of injury based on ankle fracture radiographs. Although the consistency of the LaugeHansen system (65\%) was reported as lower than that of the AO classification system (81\%) (13), all SAD injuries were correlated between videos and radiographs $(13,14)$. Type II SAD MMFs result from forced talar adduction. Failure of the lateral side combined with a vertical axial load causes the talus to tilt, and a subsequent shearing compression 
Table 4 Functional outcomes and complications

\begin{tabular}{|c|c|c|c|}
\hline Functional outcomes and complications & Buttress plate fixation $(n=30)$ & Screws fixation $(n=23)$ & $P$ value \\
\hline VAS score (SD) & $1.7(1.3)$ & $2.6(2.1)$ & 0.06 \\
\hline GTE [\%] & 25 [83] & 18 [78] & 0.64 \\
\hline FWB time (w) (SD) & $11.5(1.6)$ & $12.6(2.3)$ & 0.04 \\
\hline Wound complication [\%] & $4[13]$ & $1[4]$ & 0.37 \\
\hline Infection [\%] & $2[7]$ & $1[4]$ & 1.00 \\
\hline TOA [\%] & $3[10]$ & $4[17]$ & 0.45 \\
\hline Failure [\%] & $0[0]$ & $3[13]$ & 0.08 \\
\hline
\end{tabular}

AOFAS, American Orthopedic Foot and Ankle Society; SD, standard deviation; LoR, loss of reduction; VAS, visual analogue scale; GTE, good to excellent rate; FWB, full weight-bearing; TOA, traumatic osteoarthritis.

fracture of the medial malleolus. This type of MMF is characterized by relatively vertical fracture lines, and in some cases may present with a proximal medial cortical comminuted fracture (Figure $1 A$ ), a die-punch fragment (Figure 1B), compression and collapse of the medial part of DTAS (Figure 1C), and sometimes these characteristics may present simultaneously.

To our knowledge, no previous study has focused on the characteristics of vertical MMFs. The purpose of current study is to bring attention to the pathoanatomical characteristics and the different injury patterns associated with SAD type-II MMFs. The fractures associated with vertical MMFs are not so much simple. According to current results, the simple vertical MMF with one fracture line just accounted $39.6 \%$ of all fractures. Medial cortex comminuted fractures were much more common and accounted almost half of all this type MMFs. The TOA and LoR rate were not significantly increased in medial cortex comminuted MMFs while compared with others. However, the mean post-operative AOFAS score was significantly lower in these cases. That might because of the three failure cases were all characteristics with comminuted medial cortex. If the three failure cases were excluded, the mean AOFAS increased to $81.4 \pm 9.3$ points, and no significant was reached any more $(\mathrm{P}=0.08)$. The die-punch fragment and medial articular surface compression were coexisted in most of these types' cases (68\%, Figure 4). McConnell and Tornetta (3) reported eight SAD type-II cases with marginal impaction of the medial tibial plafond, and emphasized that anatomic reduction was essential to the prevention of early arthrosis for this type of fractures. According to current results, vertical MMF with die-punch fragment was correlated with higher rate of LoR and lower AOFAS scores; and the joint compression was correlated with higher TOA and LoR rate, and with lower AOFAS scores. After the three failure cases were excluded, the mean AOFAS scores were still lower in the two groups $(\mathrm{P}<0.05)$.

Even though there have been many published reports of operative treatment of MMFs, very few comparative clinical studies have focused on comparison of internal fixation methods for the MMFs. Mohammed et al. (15) reported the only clinical comparative study focused on tension bands wiring and screw fixation; however, the participants were all Weber type B or C fractures. To the best of our knowledge, ours is the first clinical study focused on the functional outcomes and complications of two fixation methods for SAD type II MMFs.

Various fixation methods for MMFs have been reported in the literature. However, for SAD type II MMFs, the most commonly used fixation methods can be classified into two groups, lag screws fixation or buttress plate fixation $(16,17)$. Because of the relatively vertical fracture line, tension band wiring fixation has rarely been applied in such cases. Some biomechanical studies have compared the two fixation methods for vertical MMFs $(8,9,18)$. Toolan et al. (8) compared five fixation methods for vertical MMFs, and reported that the use of a buttress plate, with or without a distal lag screw, did not offer any advantage over lag screw fixation alone. However, other biomechanical studies have supported the use of a buttress plate for vertical shearing intraarticular fractures 
$(9,18,19)$. Wegner et al. (9) reported that the buttress plate fixation of vertical medial malleolus fractures provides stiffer initial fixation than bicortical or unicortical screw fixation. Jones et al. (20) reported that the buttress plate (a 1/3 tubular plate was used) exhibited a stable, strong construct for fixation of vertical MMFs when compared with a hook plate. However, if a lag screw was combined with the buttress plate, the results were biomechanically superior to those of simple buttress plate fixation or hook plate fixation (20).

Nondisplaced medial malleolus fractures can usually be treated with cast immobilization; however, nondisplacement is rare in SAD type II injury because of the associated vertical violent force. Surgical reduction is necessary in this type of fracture because persistent displacement allows the talus to tilt into varus (21). Our mean 5 years follow up showed that ORIF of SAD type II MMF achieved good functional outcomes, and had a GTE of $81 \%$. If the 3 cases of failure were excluded, the mean AOFAS score could reach a mean of 83.8 [63-97] points, with a GTE of $86 \%$. Yu et al. (22) followed 23 SAD type II cases wherein 17 MMFs were fixed with buttress plate, and 6 with lag screws, and reported 1 instance of hardware loosening in the lag screws group. Ricci et al. (23) reported the loosening rate of lag screws fixation for MMF was as high as 13\% (12/92), and was especially prevalent among those with partially threaded cancellous lag screws (24\%). Ebraheim et al. (4) reported that among $111 \mathrm{MMFs}$, buttress plate fixations were used in 7 vertical fractures with no incidence of failure, and the mean AOFAS score was 84 points. The fracture mechanism and characteristics of SAD type II MMF are similar to those of posterior pilon fracture. Retrospective comparative studies have reported that buttress plate fixation for posterior pilon fractures showed better functional outcomes and less complications in comparison with lag screws fixation $(18,24,25)$.

According to the current results, participants who underwent fixation of vertical MMFs with a buttress plate could commence FWB exercises earlier than those who received with lag screws fixation $(\mathrm{P}=0.04)$. Tan et al. (26) reported that no significant fracture displacement, hardware failure, or new fractures occurred in a cadaveric model of early weight-bearing on an unstable ankle fracture after ORIF. However, for ankle fractures caused by vertical violence, no matter medial or posterior malleolus, the injury mechanisms are more similar to pilon fractures, with a relative vertical fracture line and a small angle to the axis of tibia which cause a larger shear force between the fracture fragment and distal tibia. Many biomechanical studies have confirmed that buttress plate fixation for this type of intraarticular fracture achieves better stabilization than that of lag screws fixation $(9,18-20)$. In our lag screw fixation group, 3 cases were diagnosed as failures and were further treated with revision surgeries. There was 1 case of fracture nonunion and fixation failure, and the other 2 cases were LoR with medial malleolus varus malunion. Although statistical analysis of failure rate detected no significant difference between groups, a failure rate as high as $13 \%$ was unacceptable, and such failure might bring disastrous ramifications to the patient. For intraarticular fractures, late TOA is unavoidable. Lübbeke $e t$ al. (27) reported that ankle fracture associated with medial malleolus has significantly large relative risks ( $R R s=2.5)$ and $95 \%$ confidence intervals (95\% CIs: 1.5 to 4.4); thus, anatomical reduction and rigid fixation is of vital importance in the treatment of SAD type II MMF. Among our participants, TOA change radiographically detected in 7 cases; 4 of whom had no clinical symptoms, and the other 3 were treated conservatively.

The limitations of current study include the retrospective design, and the lack of random group allocation. We do agree that robust study design can yield a high level of evidence for treatment decision making; however, SAD type II injury is less common than other types of ankle fractures $(2-4)$, and the baselines of the two groups were similar in our study. Our results confirmed the findings of previous biomechanical studies that buttress plate fixation of vertical MMF provides better mechanical support and stable fixation. The participants with buttress plate fixation could start FWB earlier, and had a lower rate of hardware failure. According to the current results, further well designed prospective comparative studies focused on the different fixation methods for vertical MMFs are still needed.

In conclusion, according to current study, more than $60 \%$ of vertical MMFs are with one or more characteristics of medial cortex comminuted fractures, or die-punch fragments, or medial joint compression. And patients with die-punch fragment, medial joint compression, LoR, large DTAS involvement and small FLA were positively correlated with the fair to poor clinical results. Lag screws and buttress plate fixation both can be used in this type MMFs, but the lag screw should be cautiously used in patients with comminuted medial cortex.

\section{Acknowledgments}

Funding: HZ, Key R \& D plan of Shaanxi Province (No. 
2021SF-025), Scientific research projects of Xi'an Health Commission (No. 2021ms07).

\section{Footnote}

Reporting Checklist: The authors have completed the STROBE reporting checklist. Available at https://dx.doi. org/10.21037/apm-21-1505

Data Sharing Statement: Available at https://dx.doi. org/10.21037/apm-21-1505

Conflicts of Interest: All authors have completed the ICMJE uniform disclosure form (available at https://dx.doi. org/10.21037/apm-21-1505). The authors have no conflicts of interest to declare.

Ethical Statement: The authors are accountable for all aspects of the work in ensuring that questions related to the accuracy or integrity of any part of the work are appropriately investigated and resolved. All procedures performed in this study involving human participants were in accordance with the Declaration of Helsinki (as revised in 2013). The study was approved by institutional ethics board of the Honghui Hospital Affiliated to Medical College of Xi'an Jiaotong University (No.: 20170003). Individual consent for this retrospective analysis was waived.

Open Access Statement: This is an Open Access article distributed in accordance with the Creative Commons Attribution-NonCommercial-NoDerivs 4.0 International License (CC BY-NC-ND 4.0), which permits the noncommercial replication and distribution of the article with the strict proviso that no changes or edits are made and the original work is properly cited (including links to both the formal publication through the relevant DOI and the license). See: https://creativecommons.org/licenses/by-nc-nd/4.0/.

\section{References}

1. Scott AM. Diagnosis and treatment of ankle fractures. Radiol Technol 2010;81:457-75. Erratum in: Radiol Technol 2011;83:56.

2. Warner SJ, Garner MR, Hinds RM, et al. Correlation between the Lauge-Hansen classification and ligament injuries in ankle fractures. J Orthop Trauma 2015;29:574-8.

3. McConnell T, Tornetta P 3rd. Marginal plafond impaction in association with supination-adduction ankle fractures: a report of eight cases. J Orthop Trauma 2001;15:447-9.

4. Ebraheim NA, Ludwig T, Weston JT, et al. Comparison of surgical techniques of 111 medial malleolar fractures classified by fracture geometry. Foot Ankle Int 2014;35:471-7.

5. Amorosa LF, Brown GD, Greisberg J. A surgical approach to posterior pilon fractures. J Orthop Trauma 2010;24:188-93.

6. Wang L, Shi ZM, Zhang CQ, et al. Trimalleolar fracture with involvement of the entire posterior plafond. Foot Ankle Int 2011;32:774-81.

7. Erdem MN, Erken HY, Burc H, et al. Comparison of lag screw versus buttress plate fixation of posterior malleolar fractures. Foot Ankle Int 2014;35:1022-30.

8. Toolan BC, Koval KJ, Kummer FJ, et al. Vertical shear fractures of the medial malleolus: a biomechanical study of five internal fixation techniques. Foot Ankle Int 1994;15:483-9.

9. Wegner AM, Wolinsky PR, Robbins MA, et al. Antiglide plating of vertical medial malleolus fractures provides stiffer initial fixation than bicortical or unicortical screw fixation. Clin Biomech (Bristol, Avon) 2016;31:29-32.

10. Gustilo RB, Mendoza RM, Williams DN. Problems in the management of type III (severe) open fractures: a new classification of type III open fractures. J Trauma 1984;24:742-6.

11. van Dijk CN, Verhagen RA, Tol JL. Arthroscopy for problems after ankle fracture. J Bone Joint Surg Br 1997;79:280-4.

12. Kitaoka HB, Alexander IJ, Adelaar RS, et al. Clinical rating systems for the ankle-hindfoot, midfoot, hallux, and lesser toes. Foot Ankle Int 1994;15:349-53.

13. Rodriguez EK, Kwon JY, Herder LM, et al. Correlation of AO and Lauge-Hansen classification systems for ankle fractures to the mechanism of injury. Foot Ankle Int 2013;34:1516-20.

14. Kwon JY, Chacko AT, Kadzielski JJ, et al. A novel methodology for the study of injury mechanism: ankle fracture analysis using injury videos posted on You'Tube. com. J Orthop Trauma 2010;24:477-82.

15. Mohammed AA, Abbas KA, Mawlood AS. A comparative study in fixation methods of medial malleolus fractures between tension bands wiring and screw fixation. Springerplus 2016;5:530.

16. Chen Y, Zhang H, Huang F, et al. Application of lateral malleolus hook-plate in treatment of stage II supinationadduction type medial malleolus fracture. Zhongguo Xiu Fu Chong Jian Wai Ke Za Zhi 2014;28:1077-81. 
17. Blake S, Yakubek G, Shaer J. Use of a locked fibular plate for fixation of a vertical shear medial malleolus fracture: a case report. J Foot Ankle Surg 2015;54:1202-5.

18. Zhao H, Liang X, Yu G, et al. Effectiveness and biomechanical analysis of three fixation methods in treatment of posterior Pilon fractures. Zhongguo Xiu Fu Chong Jian Wai Ke Za Zhi 2013;27:1190-5.

19. Bennett C, Behn A, Daoud A, et al. Buttress plating versus anterior-to-posterior lag screws for fixation of the posterior malleolus: a biomechanical study. J Orthop Trauma 2016;30:664-9.

20. Jones DA, Cannada LK, Bledsoe JG. Are hook plates advantageous compared to antiglide plates for vertical shear malleolar fractures? Am J Orthop (Belle Mead NJ) 2016;45:E98-102.

21. Michelson JD. Fractures about the ankle. J Bone Joint Surg Am 1995;77:142-52.

22. Yu GR, Fan J, Zhou JQ, et al. Treatment strategies for grade II supination adduction ankle fractures. Chin J Trauma 2011;27:336-40.

Cite this article as: Zhang J, Zhang Y, Liang J, Liu P, Zhao H. Pathoanatomy and clinical outcomes following operative treatment of supination adduction type II medial malleolus fractures-a cohort study. Ann Palliat Med 2021;10(7):78027812. doi: 10.21037/apm-21-1505
23. Ricci WM, Tornetta P, Borrelli J Jr. Lag screw fixation of medial malleolar fractures: a biomechanical, radiographic, and clinical comparison of unicortical partially threaded lag screws and bicortical fully threaded lag screws. J Orthop Trauma 2012;26:602-6.

24. Huber M, Stutz P, Gerber C. Open reduction and internal fixation of the posterior malleolus with a posterior antiglide plate using a postero-lateral approach: a preliminary report. J Foot Ankle Surg 1996;2:95-103.

25. De Vries JS, Wijgman AJ, Sierevelt IN, et al. Longterm results of ankle fractures with a posterior malleolar fragment. J Foot Ankle Surg 2005;44:211-7.

26. Tan EW, Sirisreetreerux N, Paez AG, et al. Early weightbearing after operatively treated ankle fractures: a biomechanical analysis. Foot Ankle Int 2016;37:652-8.

27. Lübbeke A, Salvo D, Stern R, et al. Risk factors for posttraumatic osteoarthritis of the ankle: an eighteen year follow-up study. Int Orthop 2012;36:1403-10.

(English Language Editor: J. Jones) 